\title{
L'espace funéraire de Bobigny : du cimetière aux carrés musulmans (1934-2006)
}

The Burial Area in Bobigny: from the Cemetery to the Muslims Sections

(1934-2006)

El espacio funerario de Bobigny: del cementerio a las parcelas musulmanes

(1934-2006)

\section{Soraya El Alaoui}

\section{OpenEdition}

\section{Journals}

Édition électronique

URL : https://journals.openedition.org/remi/6006

DOI : 10.4000/remi.6006

ISSN : $1777-5418$

Éditeur

Université de Poitiers

Édition imprimée

Date de publication : 1 septembre 2012

Pagination : $27-49$

ISBN : 979-10-90426-05-4

ISSN : 0765-0752

\section{Référence électronique}

Soraya El Alaoui, «L'espace funéraire de Bobigny : du cimetière aux carrés musulmans (1934-2006) », Revue européenne des migrations internationales [En ligne], vol. 28 - n³ | 2012, mis en ligne le 01 septembre 2015, consulté le 15 avril 2022. URL : http://journals.openedition.org/remi/6006 ; DOI : https://doi.org/10.4000/remi.6006 


\section{L'espace funéraire de Bobigny : du cimetière aux carrés musulmans (1934-2006)}

\section{Soraya El Alaoui ${ }^{1}$}

Si aujourd'hui la majeure partie des musulmans de France choisit d'être inhumée dans les pays d'origine, on observe cependant que ces rapatriements tendent à diminuer; en 2007, $85 \%$ des corps sont rapatriés contre $95 \%$ en 1997 (Godard et Taussig, 2007). Pour Papi (2007), le nombre peu élevé de carrés confessionnels musulmans constituerait une des raisons principales de cet exode post-mortem. On peut aussi rajouter à cela, la peur de l'exhumation liée aux concessions à durée limitée ainsi que leur prix.

Les rares études sur les cimetières, où plutôt sur les carrés musulmans en France, invitent cependant à mettre en scène cette nouvelle pratique culturelle qu'est l'inhumation de musulmans hors de l'espace traditionnel. Sous l'impulsion des travaux entrepris par le sociologue Yassine Chaïb, des chercheurs se sont intéressés à la question de I'inhumation des musulmans en France et de leur rapatriement (Chaïb, 2000, 2002, 2003 et 2004). Marie-Ange d'Adler par exemple a abordé l'étude du cimetière musulman de Bobigny dans sa recherche sur l'immigration algérienne. Elle a pu dégager le profil socioculturel des premiers inhumés et effectuer une étude du carré militaire (Adler, 2005). Quant à Atmane Aggoun, il a analysé le rôle des " patrimonialisateurs " qui ont utilisé ce cimetière pour revendiquer une mémoire et écrire une histoire musulmane en France (Aggoun, 2009). Ces différentes contributions ont ainsi participé à sortir ce cimetière de l'oubli. D'autres recherches ont ouvert de nouvelles pistes : celles de Michel Renard qui portent sur les carrés militaires musulmans en France ${ }^{2}$; celles d'Atmane Aggoun qui abordent la thématique de la mort par le biais du vieillissement des populations maghrébines (Aggoun, 2006), celles enfin d'Émile Serfati qui propose une monographie des carrés musulmans alsaciens (Serfati, 2003 et 2004). Ces différentes recherches s'appuient largement sur les travaux pionniers de Yassine Chaïb, mais elles ont le mérite de donner une plus grande visibilité à la thématique de la mort et à sa gestion dans un espace non musulman. II convient aussi de préciser que cette littérature, et les questions qu'elle suscite, a été enrichie par une production juridique (circulaires, rapports, articles juridiques) liée en partie aux revendications des associations islamiques pour la création de lieux d'inhumation musulmans ${ }^{3}$.

1 Chercheure indépendante, 1 rue du Bois du Parc, 35190 Cardroc ; soraya.elalaoui@gmail.com

2 Pour les publications de Michel Renard, cf. http://islamenfrance.canalblog.com/

3 Circulaire ministérielle du 28 novembre 1975 ; circulaire ministérielle du 14 février 1991 ; circulaire du 19 février 2008 (cette circulaire abroge et remplace les deux précédemment). Sueur et Lecerf (Sénateurs) (2005-2006) ; Machelon (2006) ; Papi (2007) ; Guillaumont (2008). 
Cet article se veut une contribution à cette thématique de l'inhumation des musulmans en France prenant pour entrée le cimetière musulman de Bobigny. II s'appuie sur la gestion privée du cimetière qui couvre la période allant de 1934 (décision de créer ce lieu) à 1997, date à laquelle il perd son statut dérogatoire et tombe dans le droit public. II s'intéresse plus particulièrement aux différentes minorités mises en scènes par les carrés qui leur sont réservés. II s'agit aussi de mettre en relief d'autres formes d'immigration, souvent marginalisées dans I'histoire de l'immigration en France.

\section{Un cimetière musulman dans un contexte laïc}

Le cimetière musulman de Bobigny est I'unique cimetière de France métropolitaine créé par décret le 4 janvier 1934. II regroupe des inhumés originaires de toutes les aires géographiques du monde musulman (Maghreb, Afrique sub-saharienne, Asie, Europe, Moyen-Orient) ou des convertis à l'islam, soit dans le cadre d'une union matrimoniale soit par engagement religieux. Dès lors, ce lieu particulier reflète une réalité de la diversité migratoire rarement soulignée dans les différentes études centrées sur l'immigration maghrébine en France.

Ce cimetière, que l'on peut considérer comme unique en son genre, englobe les deux principales branches de l'islam : sunnisme et shiisme (Mervin, 2010 ; Laoust, 1965)4. Dans les pays où ils sont représentés, comme dans le cas du Liban ou de l'Iraq, les inhumés sont enterrés selon leur appartenance religieuse et disposent de leur propre cimetière. Dans cet espace funéraire et dans un pays non-musulman, les inhumés sont donc tous rassemblés au-delà des différents courants de l'islam auxquels ils sont rattachés sans que ceux-ci soient visibles spatialement.

Les tombes des défunts évoquent des périodes de l'histoire de la France et de son empire colonial, mais aussi celles des bouleversements politiques dans des pays du Moyen-Orient, du Caucase du nord et en Turquie. En effet les personnes inhumées en France viennent de pays ayant des liens historiques et politiques avec la France : soit par la colonisation (Algérie) soit par le protectorat (Tunisie et Maroc) ou le mandat (Liban et Syrie). Ces liens résultent également du partage d'une culture francophone : c'est le cas de la Turquie sous le règne d'Attaturk (de nombreux inhumés dans le cimetière sont des étudiants turcs venus en France afin de poursuivre leurs études). C'est aussi le cas des Caucasiens du nord ou encore des Malgaches et des Comoriens ismaélites qui, suite à de nombreuses répressions subies dans leur pays dans les années 1970, se sont exilés en France (Blanchy, 2000). La présence des Turcs est également liée à l'exil politique marqué par la fin de l'Empire ottoman et la naissance de la République turque.

Ce cimetière est né d'une volonté politique coloniale qui s'était déjà exprimée par la création de la Mosquée de Paris en 1926 et par celle, en 1935, de l'Hôpital francomusulman de Bobigny auquel le cimetière est rattaché. En 1931, le président du conseil de la Seine, Pierre Godin, voyait dans la réalisation du cimetière musulman " un fait politique de la plus haute importance " au même titre que l'était l'édification de la

\footnotetext{
4 C'est un conflit, la bataille de Siffin (juin/juillet 657 correspondant au mois de Moharram 37 de I'année hégirienne) concernant la succession du califat qui a provoqué la scission des musulmans en deux groupes. Le sunnisme est le courant religieux majoritaire de l'islam ; il représente 85 à $90 \%$ des musulmans. Le shiisme qui englobe les partisans de ${ }^{c}$ Ali connaîtra une nouvelle scission au VIIle siècle donnant ainsi naissance à deux mouvements religieux : les duodécimains et les ismaélites. Au Xle siècle, un nouveau conflit de succession pour le califat provoque la division du mouvement ismaélite en deux branches rivales : la Mustaliyya ou Tayyibites et la Nizariya (ceux qui suivent l'Aga Khan).
} 
Mosquée de Paris : "Est-il besoin de dire que notre respect de leur religion est absolu? C'est l'honneur de toute notre histoire d'avoir fait de nous les défenseurs et les croyants du droit individuel des consciences. Nous n'avons pas besoin de rappeler ici que ce n'est pas sans notre aide que I'Institut musulman a pu se créer. Nous aimons mieux signaler ce fait nouveau, que le service des Affaires nord-africaines étudie actuellement, en accord avec la Société des Habous des lieux saints de l'islam, la possibilité de l'achat d'un terrain qui serait destiné à permettre l'inhumation des musulmans dans un cimetière spécial, déclaré Terre d'islam. C'est un principe bien connu que celui qui fait à tout musulman une obligation d'être enterré en terre d'islam, et nous avons eu l'occasion de constater quels frais énormes s'imposent certaines familles pour ramener en Afrique le corps de leurs membres décédés en métropole. La réalisation de notre idée donnera aux musulmans un nouveau témoignage du respect dont nous entourons leurs conceptions de la vie morale et leurs usages sociaux".

Comme le rappelle Yassine Chaïb, " la création de la Mosquée de Paris et de l'Hôpital franco-musulman avec le cimetière musulman furent des mesures symboliques, dans un contexte de célébration de la Colonisation de l'Algérie et la prise en compte de la participation de nombreux musulmans tombés à la guerre de 1914-1918 " (Chaïb, 2000 : 69). Deux terrains furent choisis à Bobigny : I'un situé au lieu-dit "L'Eau Bonne " I'autre en bordure de I'Hôpital franco-musulman. Tous deux firent l'objet de rapports défavorables en date respectivement des 30 avril et 22 septembre 1931, I'eau se présentant à quelques décimètres de la surface du sol. La direction des affaires départementales demanda alors l'examen d'une parcelle domaniale sise à Bobigny au lieu-dit "La Haute Borne " qui couvrait une superficie de trois hectares. "La contexture de ce terrain est parfaitement adaptée à sa nouvelle destination. Le sol sec et sain suffisamment aéré devant se prêter à une combustion des corps dans des délais normaux. En résumé, le terrain visité ne soulève aucune objection d'ordre hydrogéologique ou sanitaire pour y édifier un cimetière et nous donnons un avis entièrement favorable à la poursuite de ce projet ${ }^{5}$.

Ce projet souleva néanmoins l'opposition des propriétaires de terrains limitrophes qui y virent " une menace d'anéantissement brutal de tout travail accompli pour la viabilité du lotissement ". Les membres du Comité d'intérêt local "Les Vignes " réunis en assemblée générale déposèrent à la Mairie de Bobigny une pétition de protestation le 27 novembre $1932^{6}$. Ces protestations furent vaines et le projet de création du cimetière fut entériné au plus haut niveau de l'État par Albert Lebrun, Président de la République française, le 4 janvier 1934, qui décrète dans I'article $1^{\text {er }}$ : "Est autorisé sur l'emplacement indiqué en plan ci-annexé la création à Bobigny (Seine) au lieu-dit la "Haute Borne" d'un cimetière dépendant de l'Hôpital franco-musulman de Paris et du département de la Seine et qui sera réservé à l'inhumation des personnes décédées dans cet établissement ".

Créé par décret le 4 janvier 1934 le cimetière ouvrit ses portes le 8 janvier $1937^{7}$ et fut inauguré le 12 juin 1937. Un nouveau décret datant du 23 février 1937 y autorisa l'inhumation de toute personne décédée en France. L'article $1^{\mathrm{er}}$ stipule : "Pourront être inhumés dans le cimetière en exécution du décret susvisé du 4 janvier 1934 outre les personnes décédées dans l'Hôpital franco-musulman de Paris et Département de la Seine celles dont l'inhumation y sera spécialement autorisée par le Préfet de la Seine sur la proposition du Directeur dudit Hôpital ou du Directeur de I'Institut Musulman et de la Mosquée de Paris ».

5 Projet de création d'un cimetière annexe à l'Hôpital franco-musulman à Bobigny, daté du 2 novembre 1931, Archives municipales de Bobigny.

6 Cf. Pétition des protestataires, Archives municipales de Bobigny.

7 Les inhumés décédés à Hôpital franco-musulman avant l'ouverture du cimetière musulman de

Bobigny ont été enterrés au cimetière communal de Bobigny. 
Il convient de souligner que ce cimetière a un statut dérogatoire. L'existence de cimetières confessionnels trouve son origine dans l'article 15 du décret du 23 Prairial de I'An XII. Quatre ans après la Révolution française, le décret du 23 prairial an II (1793) stipulait dans l'article 15 : "Dans les communes où l'on professe plusieurs cultes, chaque culte doit avoir un lieu d'inhumation particulier; et dans le cas où il n'y aurait qu'un seul cimetière, on le partagera par des murs, haies ou fossés en autant de parties qu'il y a de cultes différents, avec une entrée particulière pour chacune, et en proportionnant cet espace au nombre d'habitants de chaque culte ". La loi du 14 novembre 1881 abrogea l'article 15 et posa le principe de non-discrimination dans les cimetières, en supprimant I'obligation de prévoir une partie du cimetière, ou un lieu d'inhumation spécifique, pour chaque culte. Puis la loi du 5 avril 1884 interdit " d'établir dans les cimetières des distinctions ou des destinations particulières en raison des croyances ou du culte du défunt ". Ce principe de neutralité a été confirmé par la loi du 9 décembre 1905. Pour autant, les règles constituant le principe de neutralité des cimetières ne s'opposent pas à la liberté de religion des titulaires des concessions funéraires et de leurs familles : les signes et emblèmes religieux sont autorisés sur les sépultures. De même il est procédé aux cérémonies conformément aux coutumes et suivant les différents cultes.

Le décret qui permit la création du cimetière musulman de Bobigny ne peut être interprété juridiquement comme un contournement de la loi sur la neutralité des cimetières. II est dérogatoire et puise sa " légitimité " en s'appuyant sur des antécédents juridiques : " il ressort de plusieurs décisions ministérielles très formelles que les hospices peuvent être exceptionnellement autorisés à créer des cimetières spéciaux répondant à des nécessités spéciales ". L'identification de I'Hôpital franco-musulman à un hospice permettait ainsi de considérer le cimetière musulman comme un lieu d'inhumation pour indigents, ce qui eut pour conséquence d'exonérer les familles des inhumés de l'achat d'une concession. Cela permit en outre de respecter la pratique d'inhumation en terre d'islam où les concessions sont mises gratuitement à la disposition des familles pour une durée indéterminée.

Photo 1 : Modèle de stèle, ministère de la Guerre, 1915

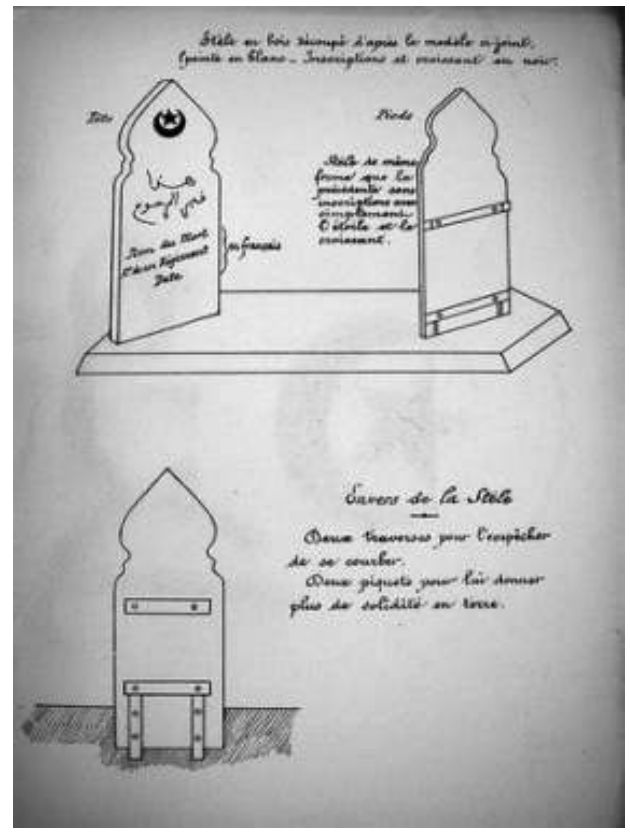

Source : Archives municipales de Bobigny. 
Au vu du modèle de stèle, le cimetière de Bobigny est aussi pensé comme un cimetière pour des musulmans maghrébins. À l'origine, la stèle reprenait, en effet, le modèle des sépultures des militaires musulmans morts lors de la Première Guerre mondiale qui avait été commandé en 1915 par le ministère de la Guerre (cf. photo 1). Cette stèle s'inspire exclusivement de l'architecture mauresque. Elle est couronnée d'une découpe en forme d'arc outrepassé (en fer à cheval) sur laquelle est consignée en graphie arabe la formule épitaphe anonyme : " hadhâ qabr al marhûm " (ceci est la tombe du rappelé à Dieu), que devait compléter la mention du nom ; le tout surmonté d'un croissant et d'une étoile, symboles du monde musulman. Pour créer un modèle de tombe musulmane, les autorités françaises eurent recours à Étienne Dinet, peintre orientaliste. Contrairement à ce qui fut décidé pour la Mosquée de Paris qui reproduit I'architecture mauresque ou I'Hôpital franco-musulman dont la porte d'entrée est une reproduction à l'identique de la porte de Mab Mansour de Meknès, le travail d'Étienne Dinet consista à rappeler des formes des sociétés maghrébines et non à reproduire un ou des modèles.

La création d'un modèle de sépulture s'oppose à la législation funéraire islamique qui préconise l'enterrement organique - en pleine terre, sans cercueil - où l'inhumé doit être orienté vers La Mecque. Cette législation interdit par ailleurs I'utilisation de pierres tombales. La forme de la tombe doit être bombée, et élevée d'une dizaine de centimètres, pour avertir de son existence afin de lui épargner d'être foulée (Brahami, 2005 : 178). Des marqueurs indicatifs, tels morceaux de bois, pierres doivent être plantés aux extrémités de la sépulture. Cependant ces matériaux ne peuvent comporter aucune inscription ni décor. Le principe est l'anonymat : aucun indice ne doit trahir la fortune ou le rang. Comme l'écritYûsuf Râgib, "la dernière demeure où le musulman sommeille en attendant le Grand Réveil n'est pas, en effet, forme libre " (Ragib, 1992 : 393-403). En effet le droit musulman définit les normes d'aménagement de la tombe (dimension, profondeur, matériaux), sa forme (plate ou bombée) comme ses signes extérieurs, qui ont uniquement pour objectif de signaler sa présence. Aussi, la législation funéraire musulmane se caractérise par une profusion de rituels avant la mise en terre, et par son contraire dès I'inhumation. Les visites des morts ne sont pas obligatoires pas plus que l'entretien des monuments funéraires, dans le cas où ils existent.

Néanmoins l'art funéraire ou plutôt les arts funéraires dits musulmans vont se construire en dehors d'une législation qui les validerait. Ils apparaissent tardivement dans le monde musulman. En effet, l'islam orthodoxe (sunnite) interdit en principe le culte des morts. Le problème de l'existence d'une architecture funéraire s'est d'ailleurs posé dès la mort du Prophète Mohammad, en 632. Fallait-il honorer sa tombe, à la façon des grands rois antiques, ou cela serait-il perçu comme une hérésie, proche de l'idolâtrie ? Finalement, Mohammad fut enterré à Médine, la "ville du Prophète ", au sein de son ancienne maison, devenue la mosquée primordiale ; toute manifestation trop démonstrative à l'égard de sa tombe est encore de nos jours sévèrement punie par les gardiens des Lieux Saints. À l'opposé des sunnites, le monde shiite présente des attitudes très différentes, avec notamment la construction d'édifices funéraires destinés à abriter les membres de la famille de ${ }^{c} A l i$ et ses successeurs, en particulier dans les villes saintes de Najaf et Kerbala en Irak. De même, la dynastie fatimide d'Égypte (909-1171) - shiite et ismaélienne - développe elle aussi les tombeaux, qui deviennent volontiers des lieux de pèlerinage (mashhad). Cette différence entre shiites et sunnites explique en partie la répartition très inégale des monuments funéraires dans l'ensemble du monde musulman. Ainsi, on est frappé en Afrique du Nord, de l'absence remarquable de tombeaux musulmans; les seuls monuments funéraires visibles dans cette région sont souvent les marbut ou " marabouts", tombeaux de saints personnages locaux, qui font volontiers l'objet d'un culte populaire. Le monde musulman oriental, et en particulier I'Iran et l'Asie centrale, présente en revanche une certaine abondance de monuments funéraires (Soustiel et Portier, $2003: 25$ ). 
Dans certains pays musulmans, la forme canonique a été évincée, car les pratiques funéraires se sont éloignées de la théorie juridique. L'examen des cimetières permet de le constater : les principes recommandés par les juristes sont oubliés. La sobriété prônée par le droit musulman pour la sépulture s'exprimera et sera interprétée selon les sociétés où l'islam (Garnier et Mohen, 2003) s'est implanté, mais toujours suivant ses deux principales branches et leurs différents rites. D'autres éléments entrent aussi en compte, en effet cette sobriété se met différemment en scène selon le milieu auquel appartient l'inhumé et sa famille : milieu rural ou citadin, niveau social, âge de l'inhumé. Parfois même les conditions du décès ont un impact sur la forme et les inscriptions. Enfin, elle sera influencée par les pratiques funéraires de la société d'accueil comme dans le cas du cimetière musulman de Bobigny.

\section{L'organisation du cimetière à l'époque de sa gestion privée : $1937-1996$}

Tout comme les formes données aux sépultures, l'organisation spatiale des tombes du cimetière de Bobigny répond à des règles spécifiques établies par des fonctionnaires musulmans rattachés à I'Hôpital franco-musulman jusqu'en 1996, date à laquelle le cimetière et non l'espace bâti, tombe dans le droit public pour être géré par le syndicat intercommunal des villes de La Courneuve, de Bobigny, de Drancy et d'Aubervilliers devenant ainsi le carré musulman de ces quatre communes. Ces fonctionnaires musulmans, généralement maghrébins, imam ou gardien, maîtrisent plus ou moins la langue française selon les cas, comme le reflète le registre $d^{\prime}$ 'inhumation où un enfant (fils du gardien) participe à le tenir à jour. L'étude du registre d'inhumation, qui a constitué une de nos sources de données, montre comment leur gestion particulière tient compte des particularités des inhumés, donnant ainsi à l'espace funéraire une cartographie inédite. Le registre d'inhumation présente, pour chaque inhumé, une ligne comprenant le nom du concessionnaire, son nom, son prénom, sa date de naissance, la date d'inhumation, l'âge au décès, le numéro du carré, celui de la ligne, de la tombe, le lieu de décès, le lieu de l'exhumation et des observations. Ces différentes informations ne sont pas toujours mentionnées. L'étude des inscriptions funéraires et d'autres sources permettent de combler les informations lacunaires du registre d'inhumation.

Le cimetière comprend une quarantaine de carrés. La numérotation des carrés prédéterminée par le concepteur du cimetière ne fut pas suivie par les gestionnaires (cf. carte 1). Ces derniers ont d'abord privilégié le remplissage des carrés les plus à l'est. L'ordre suivait plutôt une "logique religieuse " où la proximité de l'est, de La Mecque, était recherchée : carré 1 suivi du 6, etc. Par ailleurs les lignes, subdivision des carrés, " s'islamisent " en prenant pour sens de remplissage le même que celui de l'écriture arabe, de la droite vers la gauche, une hypothèse renforcée par le sens des inhumations de la gauche vers la droite, identique à celui de l'écriture du français, une fois le cimetière géré par l'intercommunale. La parcelle qui se situe à l'extrême est du cimetière a été achetée en 1959. L'espace qui se trouve dans le prolongement oriental de la salle de prière a été sciemment laissé vide d'inhumation. La salle était initialement dédiée à la prière pour les morts qui se caractérise par l'absence de génuflexion et de prosternations. Rapidement, et en raison d'un manque de lieu de culte, elle s'ouvre pour les prières rituelles, un des cinq piliers de l'islam.

À cette gestion qui privilégie l'est, on remarque certains écarts : des carrés réservés pour l'élite, les femmes, les enfants, les militaires et un enclos de sépultures indiennes (cf. carte 2). Ces distinctions en fonction du statut social, de l'origine nationale, du sexe et de l'âge n'ont aucun fondement religieux. Elles ont surtout permis une gestion maximale de l'espace funéraire. Dans le contexte d'une population immigrée musulmane très majori- 


\section{Carte 1 : Gestion privée du cimetière}

14 Numérotation initiale du CMB

6) Numérotation par ordre d'inhumation 13/06/42 Date de la première inhumation

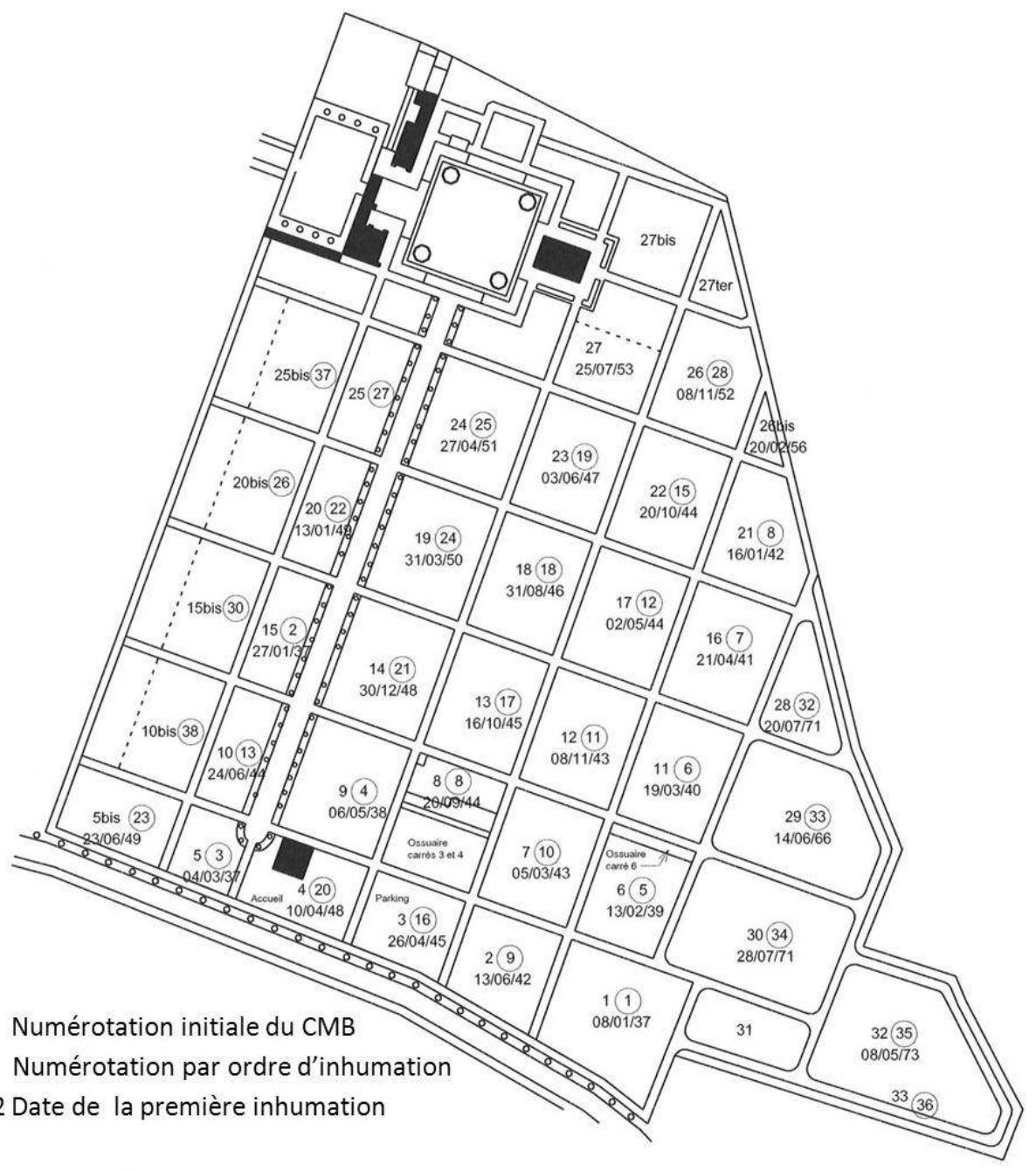

Source : S. El Alaoui 


\section{Carte 2 : Carrés réservés}

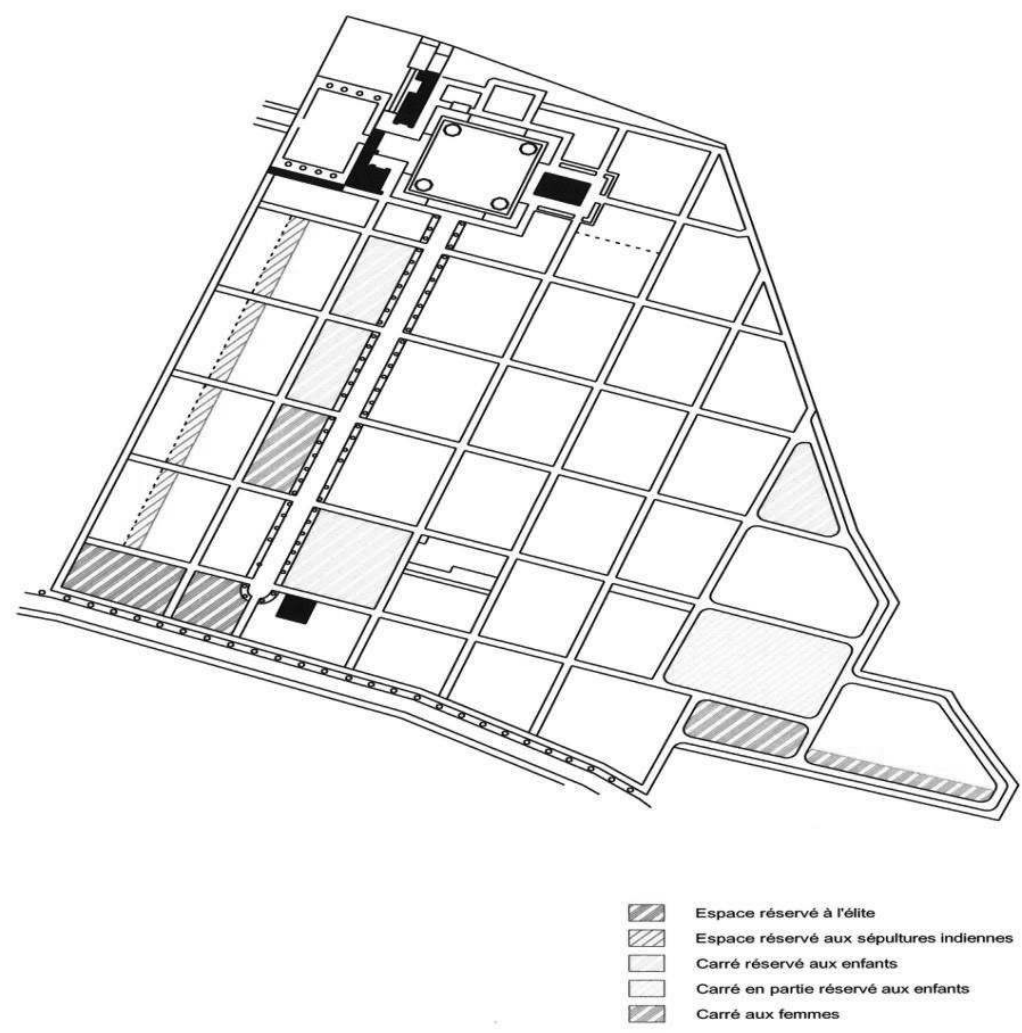

Source : S. El Alaoui 
tairement masculine et célibataire jusque dans les années 1970, la constitution de carrés réservés dès 1937 est la solution que les responsables du cimetière ont trouvée pour distinguer ces différentes minorités du reste des inhumés. Carrés réservés, ils se caractérisent aussi par une durée de remplissage beaucoup plus longue (quinze ans), par une diversité de forme de sépultures et de matériaux et par des inscriptions qui soulignent davantage encore leurs particularités.

\section{Photo 2}

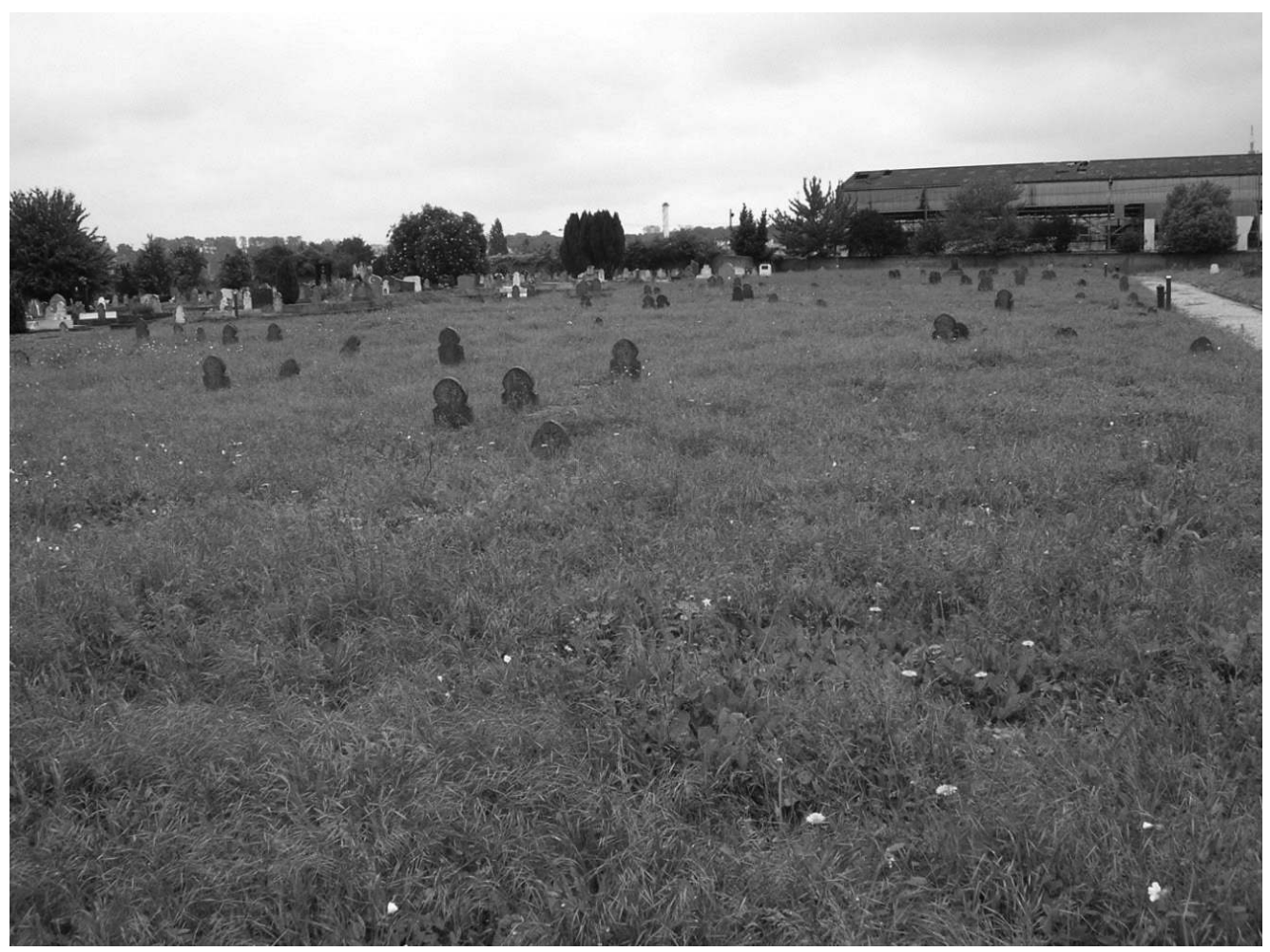

Source : S. El Alaoui

Les carrés non réservés et qui suivent la ligne orientale sont pleins environ deux ans après la première inhumation. Le profil des inhumés est homogène : ce sont généralement de jeunes ouvriers maghrébins célibataires, en particulier algériens issus de la petite et grande Kabylie et des Marocains venant de la plaine du Sous, régions de tradition migratoire. Leur décès est la conséquence d'accidents du travail liés à l'occupation de postes à risque, notamment dans le secteur de la métallurgie, des produits chimiques et de la raffinerie (Sanson, 1947). Aux accidents du travail s'ajoutaient les mauvaises conditions de vie et nombre d'entre eux sont morts de la tuberculose. Les matériaux utilisés pour leur sépulture (ciment et fer), l'absence de pierre tombale et de semelle favorisèrent I'affaissement ou la disparition des tombes. Cela contribue aujourd'hui à donner l'impression d'un paysage "vide " alors que l'espace d'inhumation est saturé (cf. photo 2). 


\section{Des élites hétérogènes}

Les carrés des élites font preuve d'une remarquable hétérogénéité. Appelés " carrés desTurcs ", " des Ottomans " " des aristos " par les usagers du cimetière, ils rassemblent très tôt une élite qui vient de tout le monde musulman et qui possède un haut niveau d'étude. Si dans l'espace de l'exil, les immigrés musulmans recherchent d'abord un espace d'inhumation qui les réunissent, il reste que le défunt de son vivant, ou sa famille, souhaitent, au-delà de la foi commune, le voisinage de celui qui est le plus proche et avec qui il partage certaines références : nationalités, milieu social, niveau d'études. En les réunissant dans des carrés ou des lignes qui leur sont affectées, les gestionnaires du cimetière ont largement contribué à signifier les particularités de ces défunts. Ainsi les carrés 5 et 5 bis sont représentatifs de l'adéquation entre gestion de l'espace funéraire et regroupement d'inhumés qui partagent des références communes.

Le regroupement de sépultures selon la nationalité, l'ethnie, et par conséquent la manière de gérer l'espace funéraire, n'est pas spécifique aux gestionnaires du cimetière de Bobigny et peut être observé dans d'autres contextes. L'étude sur les cimetières ottomans permet de voir dans la carte des lieux d'inhumations la projection spatiale de la répartition des castes dans la société ottomane (Vatin et Yérasimos, 2001 : 51). Le cimetière parisien de Thiais permet aussi bien le regroupement confessionnel que celui de personnes originaires d'une même zone géographique : regroupement des orthodoxes slaves, des catholiques polonais, des musulmans iraniens en exil. Parmi les quinze divisions musulmanes, certaines zones sont réservées aux tombes shiites (division 19), à celles des ismaéliens (division 34, 93) et enfin à celles des " indo-musulmans " (division 90) (Frégosi et Boubekeur, 2006 : 106-107). Sur l'île de la Réunion, selon la branche à laquelle ils appartiennent, les shiites ne sont pas inhumés dans les mêmes cimetières.

Les sépultures "musulmanes " et "locales " se partagent le même espace. En effet, la forme de sépulture marquée par une ou deux stèles n'est pas l'unique modèle observable dans ces deux carrés ( 5 et 5 bis). À côté de cette forme première de sépulture, d'autres modèles de sépultures viennent différencier cet espace. Six modèles " précurseurs " ont été répertoriés. Leurs formes ne renvoient pas toujours à des référents architecturaux "islamiques ", mais seraient des modèles qu'on pourrait retrouver dans des " cimetières locaux ". La diversité des monuments funéraires est à associer à la longue durée du remplissage de ces carrés ${ }^{8}$. Cela permet de répertorier des modèles des années 1930, comme des années 1940 et 1950, mais aussi des modèles de stèles importées. Ces nouvelles formes de sépultures vont trouver plus tardivement leur place dans des carrés plus récents du cimetière musulman de Bobigny.

Le lieu du décès répertorié dans le registre des inhumations participe aussi à isoler les inhumés dans ces deux carrés. Bien que l'Hôpital franco-musulman soit souvent le lieu de décès, d'autres relèvent d'un prestige social : Hôpital américain, Clinique Léopold, Neuilly, $7 \mathrm{e}, 16 \mathrm{e}$ et $14 \mathrm{e}$ arrondissements de Paris, etc. Par ailleurs c'est parmi ces sépultures que I'on peut remarquer les lieux de décès les plus éloignés du cimetière musulman : Le Havre, Nice, Cannes, la Suisse, etc. Autre élément marquant la différence, les inscriptions relevées sur les stèles ne se limitent pas à l'identité de l'inhumé : nom et prénom comme cela est observable sur les carrés non réservés. Elles recèlent des informations qui se déclinent sous différentes formes, de manière directe ou indirecte, pour rappeler l'origine nationale et le statut social du défunt. Préciser sa nationalité sur la stèle, c'est énoncer

8 Le carré 5, ouvert le 4 mars 1937, est arrivé à saturation le 14 octobre 1953, alors que le 5bis, ouvert le 23 juin 1949 est arrivé à saturation le 4 juin 1960. 
sa différence, la nationalité étant absente sur les sépultures dans un espace musulman. Dès lors, elle devient un référent identitaire majeur. Son inscription viendrait " nationaliser " l'espace d'inhumation. Quand la nationalité est absente de la stèle, certaines formules rappellent l'exil comme par exemple "loin de la Mère Patrie ". La nationalité peut être gravée sur la stèle précédée de l'identité individuelle et accompagnée du lieu de naissance : par exemple "Afghan, Turc, né à Tabriz ". On peut aussi la connaître grâce à des formules funéraires : ainsi l'épitaphe "Ruhuna Fatiha " qu'on peut traduire par "Que ton âme soit en paix " est gravée exclusivement sur les stèles d'inhumés turcs. La langue des inscriptions est aussi un indicateur de l'appartenance nationale : turc, persan, arabe. II est également possible à l'aide de la graphie arabe et de ses points diacritiques de différencier les Orientaux des Maghrébins, mais surtout les Marocains, tout comme l'écriture cyrillique signifie la nationalité russe. Le choix du calendrier syriaque adopté au Liban et en Syrie marque aussi l'origine nationale de l'inhumé. C'est toujours dans les carrés 5 et 5bis qu'apparaît l'utilisation simultanée du calendrier hégirien avec sa correspondance grégorienne. En revanche, la référence au sunnisme ou au shiisme est rarement visible dans ces deux carrés; seul un poème, faisant l'éloge funèbre du disparu inscrit sur une sépulture iranienne, évoque par une métaphore sa filiation shiite.

\section{Photo 3}

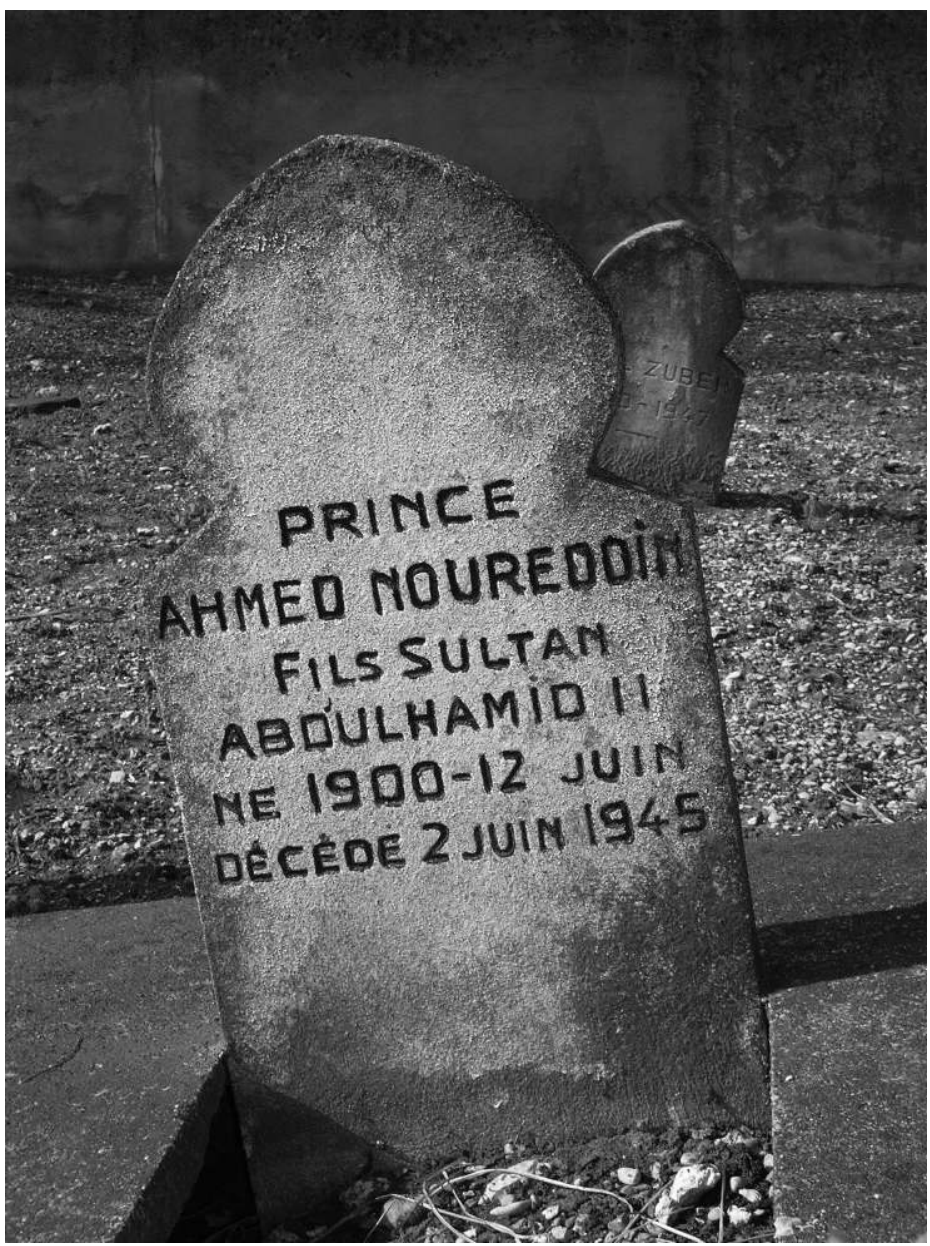

Source : S. El Alaoui 
Quant à la langue française, elle occupe une place de choix dans les inscriptions sur les stèles. Elle donne l'identité du défunt, mais elle marque surtout la différence sociale entre les inhumés de ces deux carrés et ceux des autres carrés du cimetière. Elle révèle leur niveau d'études, leurs fonctions ou leurs grades dans l'armée (étudiants, professeurs, docteurs, maréchal, général, etc.) ou encore leur appartenance à l'aristocratie (princes). Pour marquer davantage le statut de notable, la filiation de l'inhumé apparaît sur la sépulture, notamment quand elle témoigne de son appartenance aristocratique et que le titre des ascendants est hiérarchiquement plus élevé que celui de l'inhumé : Prince Ahmed Nouredinne Fils Sultan Abdulhamid II (cf. photo 3). Parfois ce marquage social met en relief d'autres liens de parenté plus nobles au détriment de la filiation directe : Mehmed Ali (1870-1937) gendre du sultan-fils du maréchal. Ces marqueurs élitistes apparaissent principalement dans d'autres langues que l'arabe. Les inscriptions en arabe mentionnent rarement le statut de l'inhumé comme si l'absence de marqueur social dans cette langue, qui est aussi celle du Coran, traduisait une fidélité à la tradition islamique où le statut social prend fin avec la mort. Enfin c'est dans ce carré que l'on observe les premières inscriptions religieuses tirées du Coran, mais aussi les formules liées au décès en France. Elles deviendront un des éléments scripturaires essentiels sur les tombes récentes. Si les inscriptions sur la stèle dénotent un niveau social élevé, elles marquent la spécificité de cette migration et en rappellent les causes : la poursuite de la scolarité en France, des raisons politiques et parfois médicales.

Le recensement des inscriptions de ces carrés laisse entrevoir I'hétérogénéité nationale des défunts qui reposent dans un même espace (Turcs, Iraniens, Caucasiens, Syriens, Égyptiens, Maghrébins, etc.) et la présence importante d'inhumés originaires du Caucase du nord, appartenant à différents groupes ethniques: Adyghéens, Tcherkesees, Kabardes, Ingouches, Tchétchènes, etc. ; tous ont été membres de la République des Montagnes du Nord-Caucase, État indépendant de mai 1918 à janvier 1921, date à laquelle les membres de ce gouvernement prennent la route de l'exil et viennent s'installer en Suisse et en France ${ }^{9}$.

La gestion de ces deux carrés reproduit des pratiques en vigueur dans les sociétés musulmanes où l'inhumation ne suit pas un ordre préétabli. Ainsi on retrouve des regroupements de la même famille (mari-femme, père-fils, cousins), bien qu'il y ait un intervalle de temps important entre leur décès. Par ailleurs la séparation homme/femme centrale dans I'organisation de ce cimetière n'est pas de rigueur dans ces carrés : par exemple, Havar Tchermoeff née Ibrahimbekova, princesse iranienne et épouse d'Abdelmajid Tchermoeff, décédée le 14 octobre 1953, repose à côté de son époux décédé le 28 août 1937.

Non sans une certaine ironie, on peut remarquer que les gestionnaires du cimetière ont parfois effacé les oppositions qu'ont pu avoir de leurs vivants certains inhumés : par exemple, al Afiouni, figure de la résistance syrienne repose non loin du neveu du pacha El Glaoui figure marocaine de la collaboration avec la France. Enfin, parmi ces sépultures de notables, celle du marathonien Boughera El Ouafi (15 octobre1898-18 octobre 1959), champion du monde aux Jeux olympiques de 1928 à Amsterdam vient donner une autre forme de prestige au carré 5 bis et suggère une conception de l'élite qui ne se limite pas à l'aristocratie.

\footnotetext{
9 Cette république a été constituée parTchermoeff (ancien militaire faisant partie de la garde rapprochée du Tsar Nicolas II et pionnier dans l'industrie pétrolière de Grozny). Après la révolution d'octobre, il rédige une convention pour la formation d'un État indépendant. La République des Montagnes du Nord-Caucase est officiellement établie le 11 mai 1918. Tchermoeff devient le Premier ministre du gouvernement. En mai 1919, lors du Traité de Versailles, il mène à Paris une délégation dont l'objectif est de faire reconnaitre en Europe l'indépendance de la République.
} 


\section{Des carrés pour les femmes et les enfants}

La première inhumation d'une femme intervient le 27 janvier 1937 c'est-à-dire moins de trois semaines après celle du premier homme inhumé dans le carré 1, le 8 janvier 1937. Le carré des femmes atteste d'une immigration familiale bien qu'elle ne soit pas une norme. Elle atteste aussi d'une volonté de gommer les différences sociales et de ne retenir que le sexe. Ici, épouses, mères ou filles, Maghrébines, Turques ou Caucasiennes, d'origines modestes ou bourgeoises; toutes reposent dans le même espace tout en ayant des sépultures très différentes. Si la richesse de l'une répond la sobriété de l'autre, dans ce carré c'est une forme "d'individualisation " de rites, perceptibles dans les formes et inscriptions des sépultures, que l'on constate.

\section{Photo 4}

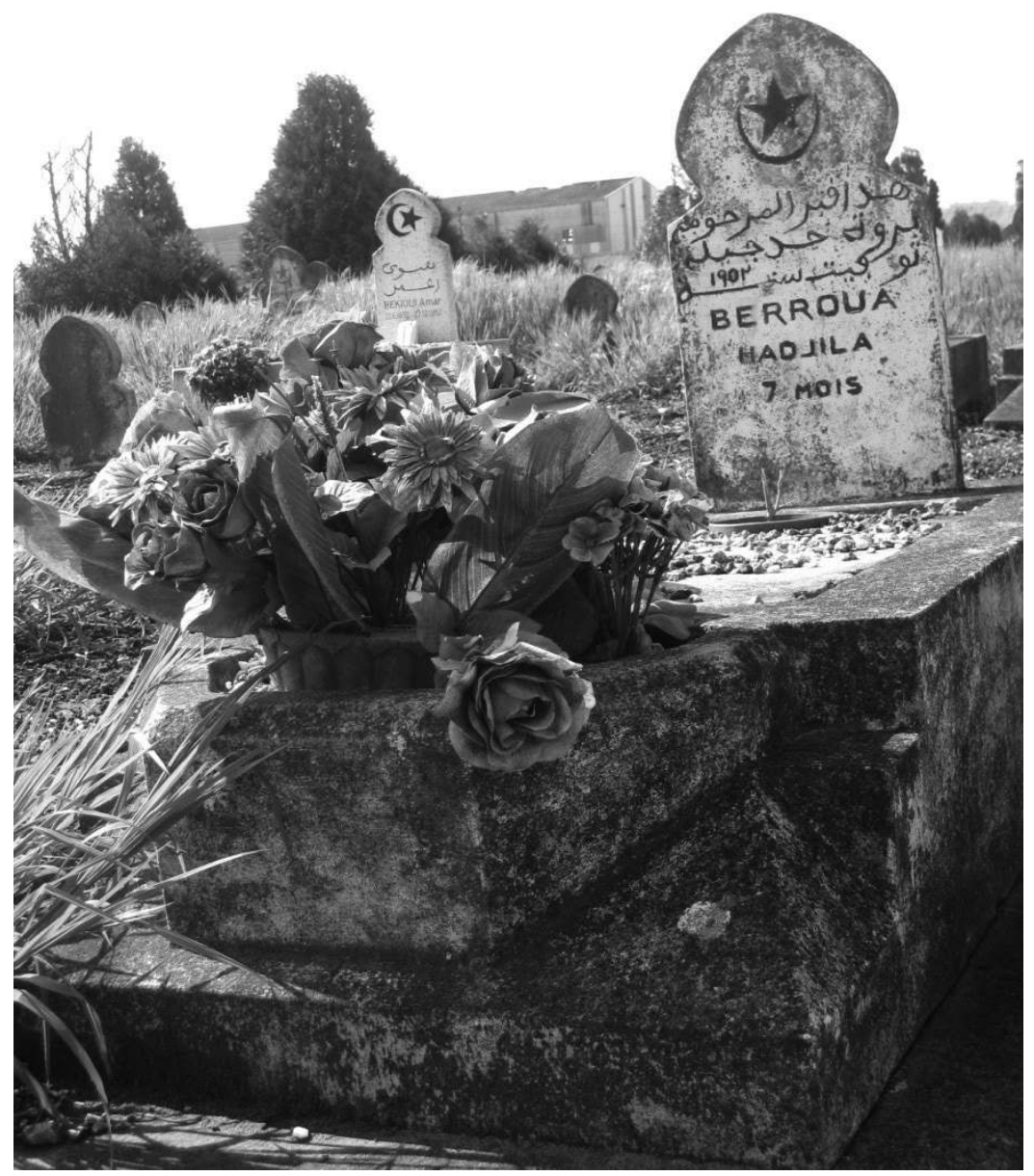

Source : S. El Alaoui 
Les carrés 9, 25, 28 et 30 sont réservés aux enfants et leur inhumation qui date de 1938 annonce les débuts d'une immigration familiale chez les immigrés musulmans. Deux aspects distinguent les sépultures, outre l'identité de l'enfant : une inscription en français, qui donne l'âge de l'enfant lors du décès et la forme des sépultures. D'une part le choix de mettre en évidence la durée de vie (un jour, huit mois, par exemple ${ }^{10}$ ) marque encore plus l'aspect tragique d'une mort prématurée (cf. photo 4), d'autre part si la stèle en forme d'arc outrepassé estampillé par les deux symboles de l'islam, est souvent le modèle repris dans ces carrés, la forme de la tombe reprend celle des enfants inhumés dans les autres cimetières locaux. La pierre tombale est fréquemment décorée d'une jardinière avec des compositions florales, souvent en plastique (cf. photo 5). On rencontre aussi des inscriptions qui reprennent des formules utilisées dans la tradition funéraire française, comme "On ne t'oubliera jamais".

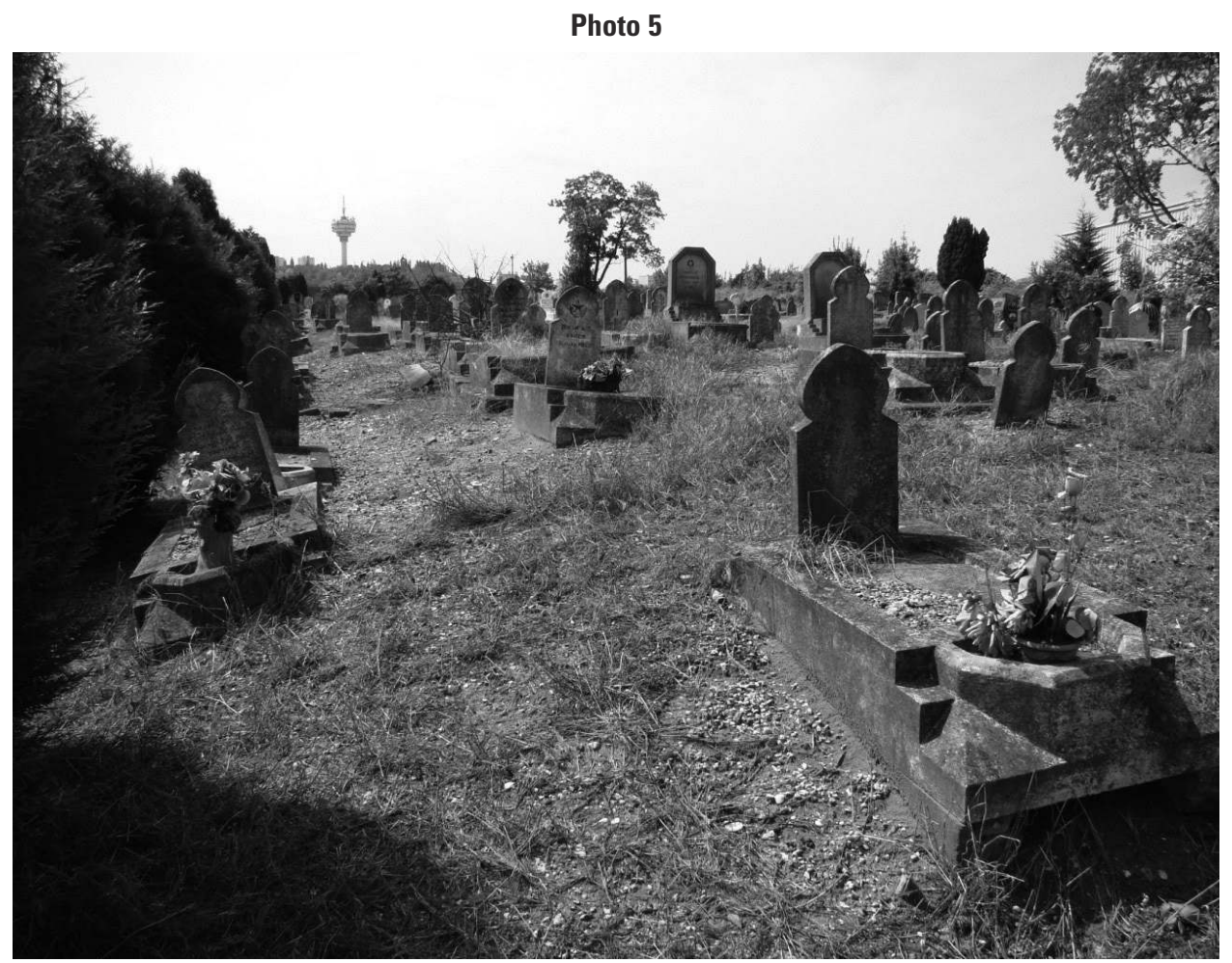

Source : S. El Alaoui

L'appropriation de pratiques liées au deuil en France signalait déjà une forme de biculturalisme funéraire qui est devenue banale aujourd'hui. Les sépultures d'enfants, que l'on compte parmi les premiers carrés du cimetière, mais aussi celles de personnes décédées à la fleur de l'âge (dix-huit à vingt-cinq ans), sont bien représentées dans les carrés anciens comme récents. La mort de ces jeunes à une incidence sur le choix de leurs parents d'être inhumés à leur côté. Par leur décès, les enfants assignent à leurs parents un nouvel espace d'inhumation, absent dans le projet migratoire. Le territoire d'inhumation n'est plus celui du pays d'origine et crée une nouvelle forme de filiation funéraire.

10 Dans le carré 9, l'âge des enfants inhumés dépasse rarement deux ans. 


\section{Le regroupement des sépultures " indiennes "}

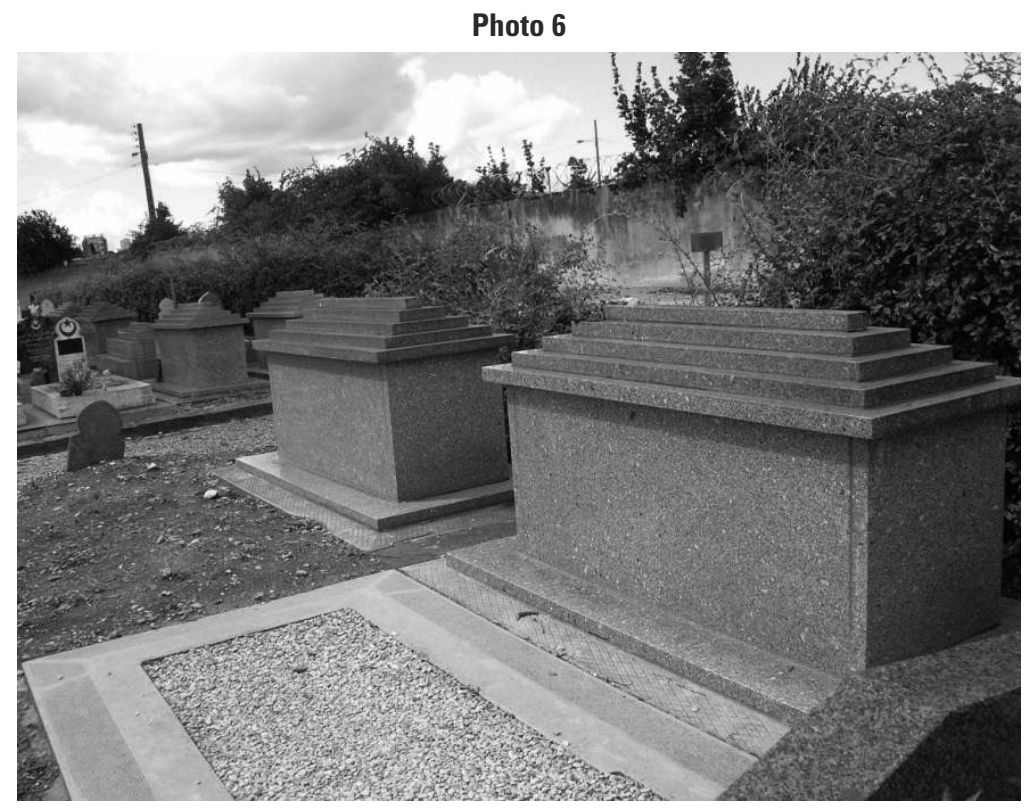

Source : S. El Alaoui

Enfin, le cimetière musulman à Bobigny comprend une quarantaine de sépultures dites "indiennes ». Elles sont réparties sur différents carrés, mais on retrouve une concentration dans les carrés 10 bis, 15 bis, 20 bis et 25 bis qui se suivent. Elles se situent toutes le long d'une haie qui longe ces carrés. La séparation végétale participe même à les mettre en valeur (cf. photo 6). Ces sépultures dites "indiennes " comportent généralement cinq gradins. Cette forme architecturale matérialise la première lignée du shiisme. Chaque niveau renvoie à ses personnages de références: Mohammad, ${ }^{c} \mathrm{Ali}$, Fatima, Hasan et Husayn. Sur chaque stèle on retrouve le nom inscrit en arabe de ces cinq figures du shiisme. Mais on peut lire aussi des inscriptions en différentes langues comme l'arabe, le gujarati, le français et l'anglais ainsi que différents chiffres arabes, indiens et gujarati (cf. photo 7). On a là un résumé de l'histoire de la communauté shiite ismaélite tayyibite originaire du Gujarat (région du nord-ouest de l'Inde) qui montre la complexité des itinéraires migratoires. Ces sépultures se distinguent par l'utilisation de chiffres qui rappellent l'aspect ésotérique de cette branche de l'ismaélisme : 786 est la somme des lettres composant la formule : "Au nom de Dieu, le Tout miséricorde, le Miséricordieux ", verset qui ouvre chaque sourate et 110 correspond au nom de ${ }^{\mathrm{A}} \mathrm{Ali}$. Le choix du gujarati indique la référence géographique originelle, le Gujarat. Et même si la majorité des inhumés sont nés ailleurs, à Madagascar ou aux Comores, c'est toujours la combinaison de la spécificité religieuse et du lieu d'origine qui renvoie à l'identité post mortem de ces inhumés. 


\section{Photo 7}

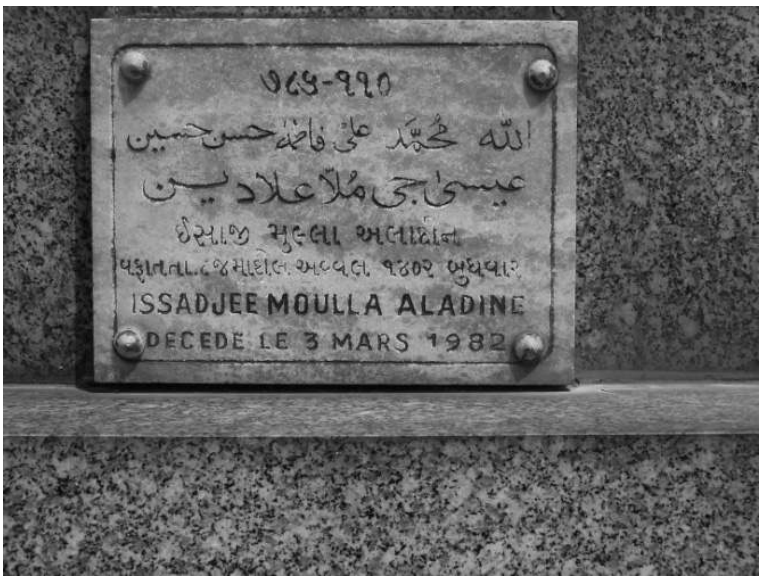

Source : S. El Alaoui

\section{L'impact du regroupement familial sur la gestion du cimetière}

Les carrés réservés vont disparaître quand les populations musulmanes, venues d'anciennes colonies françaises, se stabilisent sur le sol français. La séparation hommes/ femmes, comme le regroupement d'inhumés en fonction de leur statut social ou de leur ethnie, n'ont plus court dans la gestion du cimetière. Le cas du carré 32, ouvert en 1973, peut être qualifié de "monde musulman ". À la stabilité des populations répondent de nouvelles formes de sépultures qui ne reproduisent pas toujours le modèle initial visible dans les autres carrés, formés par deux stèles de type mauresque. D'autres formes architecturales n'incluent aucun référent à l'islam. Sur les sépultures on trouve une juxtaposition de référents identitaires à la fois religieux, nationaux et locaux. Les inscriptions religieuses sont issues du Coran et transcrites en arabe. On peut lire par exemple, La Bismillah, premier verset de toutes les sourates, La Fatiha, première sourate du Coran appelée aussi l'Ouverture, qui gravée sur une plaque mobile est l'inscription religieuse la plus représentée sur les tombes. Elle est associée parfois à des représentations qui symbolisent le monde musulman : minaret, la Kacba. On trouve encore La Shahada, ou Témoignage, le premier pilier de l'islam : " II n'y a de Dieu que Dieu, Mohamed est Son Prophète ". Parfois seule la première partie de cette formule est gravée sur les stèles. À ces versets qui rappellent l'unicité divine s'ajoutent ceux qui renvoient à la rhétorique de I'eschatologie musulmane : "Chaque âme goûtera la mort " ; " À Dieu nous sommes $A$ Lui nous retournons", "Dis: Jouissance d'ici-bas n'est que peu de chose. Meilleure est la vie dernière pour quiconque se prémunit " (Sourate IV, verset 77).

Ces inscriptions renvoient donc à différents registres de l'appartenance signifiée par le lieu de naissance, la nationalité, mais aussi les références ethniques (symbole et langue kabyles par exemple). Des " objets religieux ", nombreux, trouvent également leur place sur les tombes ${ }^{12}$ comme des autos-collants, des étendards, des gravures, etc. Le premier objet religieux reste le chapelet qui caractérise le rituel de la prière et devient une

11 Pour un responsable de pompes funèbres, les inscriptions « À Dieu nous sommes À Lui nous retournons " "Chaque âme goûtera la mort " sont les plus demandées par ses clients musulmans. 12 Par objets, nous entendons un matériau divers qui intègre une terminologie ou une symbolique islamique. 
marque d'identité. II s'accompagne de représentations de La Mecque, de mosquées ou de minarets, de plaques gravées de versets coraniques, dont la "Fatiha ", très fréquemment.

L'utilisation de procédés métaphoriques d'expression et de formules allégoriques du deuil inconnu en Islam (Chaïb, 2000 : 221) comme "Nous ne t'oublierons jamais", "le souvenir reste ", etc. témoignent de l'assimilation par les populations musulmanes des marqueurs de la société française. Les pratiques funéraires se sont différenciées au contact de la société d'accueil, elles sont aussi le résultat des propositions des responsables des pompes funèbres (des "kits funéraires " comportent des offres autres que le monument funéraire). Ces formes de "captation " par la société d'accueil vont déjà vers un syncrétisme, voire un "biculturalisme funéraire " qui va se généraliser plus tard dans les carrés gérés par l'intercommunale.

\section{Photo 8}

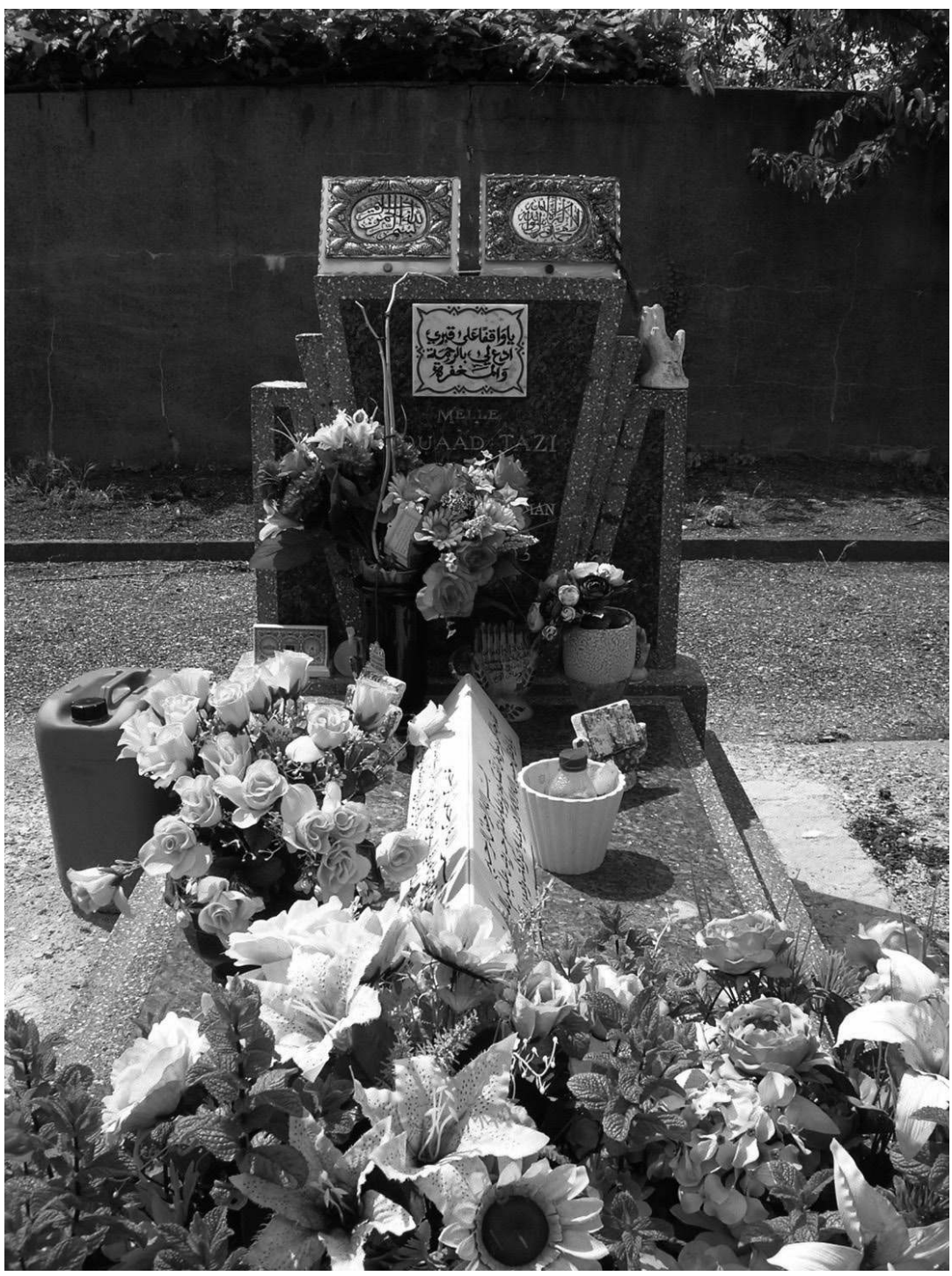

Source: S. El Alaoui 
La surcharge des sépultures particulièrement observables pour celles destinées aux jeunes (cf. photo 8), qui associent symboles locaux et symboles religieux peut être interprétée comme une démarche réparatrice alors que l'on est enterré loin de la terre natale. Cette surenchère d'objets semble compenser l'impossibilité ou la difficulté de respecter les étapes du rituel islamique - dont l'enterrement organique - dans un espace non musulman qui a ses propres codes juridiques. Pour compenser cette interdiction, les musulmans s'approprient des pratiques propres aux funérailles françaises, mais en les islamisant.

\section{La gestion intercommunale (depuis 1996)}

Le $1^{\text {er }}$ janvier 1962, I'Hôpital franco-musulman change de propriétaire. Par décret en date du 11 octobre 1961, il est rattaché à l'Administration générale de l'Assistance Publique de Paris. II demande alors à être dessaisi de la gestion du cimetière, mais cela n'interviendra effectivement qu'en 1996. L'installation du SAMU en 1974 ouvre l'hôpital à tous et clôt " son histoire musulmane " (Chevillard-Vabre, 1982). En 1978, il va changer de nom et prendre celui d'Hôpital Avicenne. Le 10 janvier 1996, I'Assistance publique et les Hôpitaux de Paris propriétaires du cimetière transmettent la gestion du cimetière au Syndicat intercommunal des villes de Bobigny, Aubervilliers, Drancy et La Courneuve. Dès lors le " cimetière musulman " perd son statut dérogatoire et devient le carré musulman du cimetière intercommunal.

Ce nouveau statut va impliquer une nouvelle gestion. Le principe de l'achat d'une concession devient obligatoire et seules les personnes domiciliées dans les quatre communes ou ayant déjà un ascendant ou un descendant inhumé peuvent y être enterrées. L'espace du cimetière va se modifier avec l'ouverture d'une nouvelle porte, la création d'un bureau d'accueil et un emplacement de stationnement ${ }^{13}$. De nouvelles pratiques d'inhumation s'installent, bien que contraires à l'esprit coranique, comme celle d'enterrer trois personnes dans une même tombe. De même l'utilisation d'une ancienne tombe pour une nouvelle inhumation d'un membre de la famille vient modifier "l'uniformité " du carré. On assiste à des " remises à jour " des formes architecturales et l'introduction de matériaux nouveaux : à la forme ogive des stèles, répond une forme plus élaborée, le ciment est remplacé par du granito-ciment.

Les nouveaux gestionnaires ont aussi procédé au déboisement de la partie ouest du cimetière ce qui a permis d'agrandir les espaces d'inhumation (cf. carte 3 ). Ceux restés " vides " dans le respect de la salle de prière et du sacrifice vont être utilisés par la suite pour les inhumations. Ces nouveaux carrés vont transformer la topographie du cimetière dans laquelle s'oppose un centre vide où le végétal prime, à une périphérie pleine de nouvelles sépultures où le minéral s'impose. Cette impression de vide entouré par un espace saturé tend cependant à disparaître avec les récentes reprises d'anciens carrés ${ }^{14}$.

\section{Conclusion}

Malgré la neutralité des espaces d'inhumation promulguée par la loi du 14 novembre 1881, la création du cimetière musulman de Bobigny a été possible grâce à des décisions politiques qui prennent leurs sources dans des antécédents juridiques pour légitimer cet espace religieux à l'intérieur d'un espace laïc. Cependant, les fonctionnaires musulmans,

13 Ces deux dernières modifications ont pu être réalisées par l'exhumation des carrés 3 et 4 dont les ossements ont été placés dans un ossuaire, derrière le carré militaire.

14 En juillet 2010, les corps du carré 6 ont été exhumés et placés dans un ossuaire (trois dernières lignes du carré) pour récupérer un nouvel espace d'inhumation. 


\section{Carte 3 : Gestion privée et gestion intercommunale}

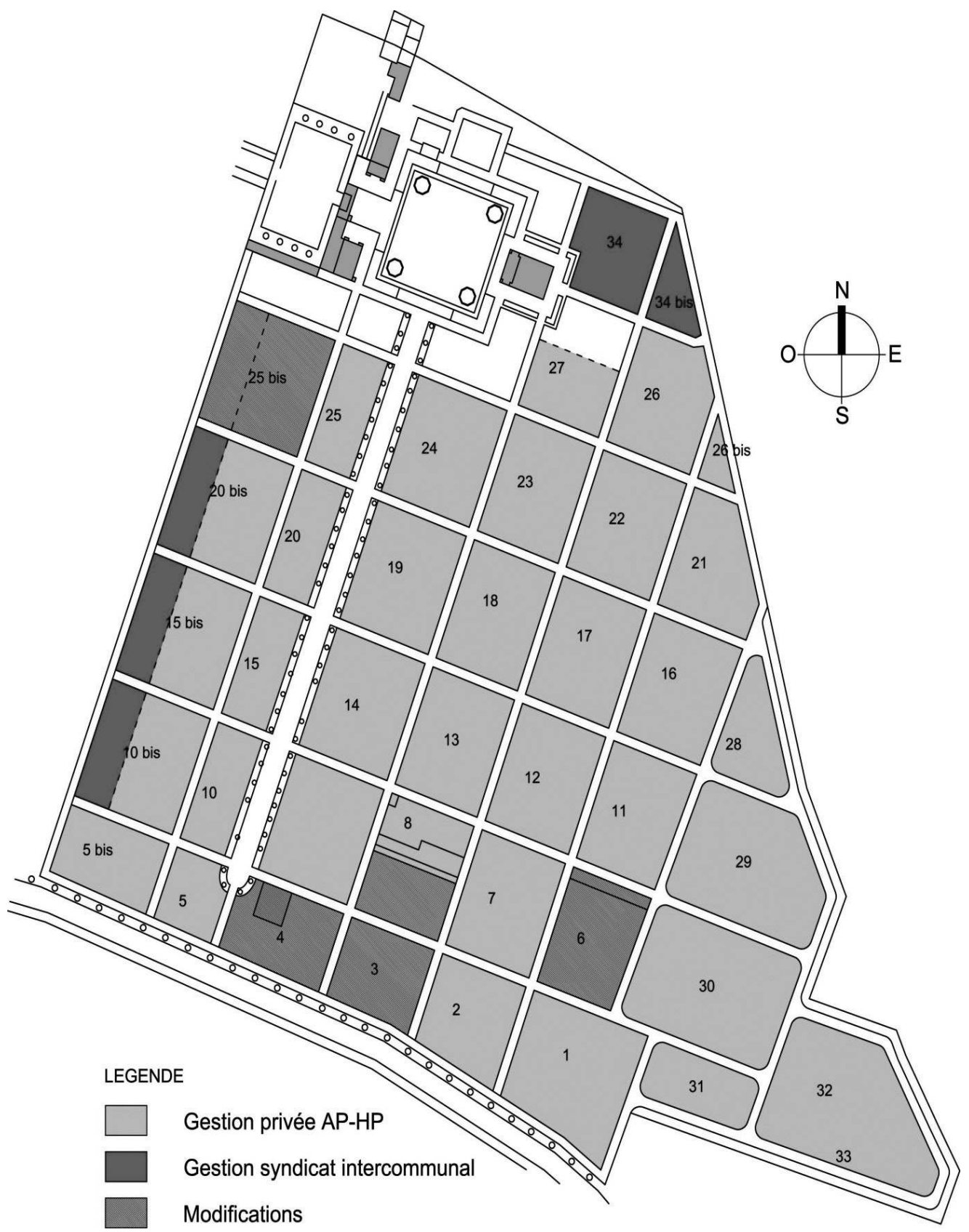

Source : S. El Alaoui 
gestionnaires du cimetière, n'ont pas toujours suivi les règles d'inhumation en vigueur dans les pays musulmans. Ils les ont ajustées à d'autres variables, notamment la diversité sociale et nationale des flux migratoires musulmans. Leur organisation du cimetière donne à voir le profil hétérogène des migrants et les raisons de leurs migrations : travail, poursuite d'études, exil politique. Elle privilégie les hiérarchies sociales (élites versus travailleurs) aux divisions religieuses (shiites versus sunnites) et aux règles musulmanes de base (séparation des femmes et des hommes). Or cette diversité des flux migratoires de la première partie du XXe siècle s'efface dès lors que les populations musulmanes s'installent en France.

L'intercommunale qui remplace les fonctionnaires musulmans à partir de 1996 organise le cimetière selon des règles exclusivement laïques qui tendent à lui donner une nouvelle topographie. En imposant comme règle l'appartenance à l'une des quatre communes pour être inhumé dans le cimetière musulman de Bobigny, elle efface la dimension nationale de cet espace funéraire au profit d'un espace local : d'un cimetière national, on passe à un cimetière local. Malgré ce changement de statut, les usagers du cimetière persistent à l'appeler cimetière musulman et non carrés musulmans des quatre communes.

L'inscription au titre des monuments historiques du porche d'entrée, de la salle de prière et du carré militaire en date du 25 juin 2006 protège ces lieux sur un périmètre de $500 \mathrm{~m}^{2}$. Cependant, deux " conceptions " se partagent un même espace donnant au cimetière musulman de Bobigny une cartographie inédite : une conception franco-musulmane inspirée par des règles religieuses adaptées à la situation migratoire ; une conception française laïque. La première tend néanmoins à disparaître aujourd'hui puisque certains carrés vont être bientôt récupérés afin de résoudre la question du manque d'espace d'inhumation.

\section{Références bibliographiques}

Adler Marie-Ange d' (2005) Le cimetière musulman de Bobigny. Lieu de mémoire d'un siècle d'immigration, Paris, Éd. Autrement, 166 p.

Aggoun Atmane (2009) Le cimetière franco-musulman de Bobigny : lieu de mémoire, traces d'immigration et patrimonialisation. Jalons pour une recherche, Études sur la mort, 2 (136), pp. 33-42.

Aggoun Atmane (2006) Les musulmans face à la mort en France, Paris, Éditions Vuibert, $156 \mathrm{p}$.

Blanchy Sophie (2000) Karana et Banyans, Les communautés commerçantes d'origine indienne à Madagascar, Paris, L'Harmattan, $346 \mathrm{p}$.

Brahami Mostafa (2005) Les rites funéraires en Islam, Lyon, Éditions Tawhid, 188 p.

Chaïb Yassine (2007) Citoyenneté et Vieillissement, Revue Migrations Santé, 127-128, pp. 56-67.

Chaïb Yassine (2006) Le rapatriement de la dépouille mortelle chez les immigrés maghrébins en France, L'Autre, 7 (3), pp. 399-411. 
Chaïb Yassine (2004) Le rite funéraire de l'intégration, Cités, Hors-série, pp. 527-535.

Chaïb Yassine (2003) Carrés musulmans, I'ultime geste d'intégration, Cahier de l'Observatoire, 37.

Chaïb Yassine (2002) Des itinéraires de migrants algériens vieillissants, Cahier de l'Observatoire, 35.

Chaïb Yassine (2001) La mort des immigrés. Mourir " ici " ou " là-bas ? ", Mémoires familiales et immigrations, Informations Sociales, 89, pp. 130-143.

Chaïb Yassine (2000) L'immigré et la mort, Aix-en-Provence, Edisud, 254 p.

Chaïb Yassine (1996a) Le rapatriement des corps, ou l'éternel retour de l'émigré, Hommes et Migrations, 1195, pp. 41-44.

Chaïb Yassine (1996b) Mouvements physiques et polarités de l'intégration : le lien post mortem. Le trépas comme passage au politique, Actes de la IX réunion de I'AFEMAM, pp. 334-335.

Chaïb Yassine (1995a) Les martyrs des uns et des autres, Penser l'Algérie, Cahiers Intersignes, 10, pp. 141-152.

Chaïb Yassine (1995b) La sépulture du naturalisé, Écarts d'identité, 75, pp. 29-32.

Chaïb Yassine (1994) La mort nomade, in L'Annuaire de l'Émigration, Maroc, Eddif, Casablanca, pp. 347-351.

Chaïb Yassine (1992) Le lieu d'enterrement comme repère migratoire, Awrâq, revue de I'Institut de Coopération avec le Monde Arabe de Madrid, 13, pp. 3-27.

Edhem Eldem (1995) L'écrit funéraire ottoman : création, reproduction, transmission, REMMM, 75-76 (1-2), pp. 65-77.

Frégosi Franck et Boubekeur Ahmed (2006) L'exercice du culte musulman en France, Lieux de prière et d'inhumation, Paris, La documentation française, $373 \mathrm{p}$.

Garnier Jean-Claude et Mohen Jean-Claude (2003) Cimetières autour du monde. Un désir d'éternité, Paris, Errance, 191 p.

Godard Bernard et Taussig Sylvie (2007) Les Musulmans en France. Courants, institutions, communautés : un état des lieux, Paris, Hachette Littératures, 454 p.

Guillemont Olivier (2008) La pratique des carrés confessionnels, La Gazette, 28 avril, [en ligne]. URL : http://www.lagazettedescommunes.com/

Laoust Henri (1965) Les schismes dans l'islam, Paris, Payot, 500 p.

Machelon Jean-Pierre (2006) Les Relations des cultes avec les pouvoirs publics, Paris, La Documentation française, $85 \mathrm{p}$.

Mervin Sabrina (2001) Histoire de I'Islam : Fondements et doctrines, Paris, Flammarion, $311 \mathrm{p}$. 
Papi Stéphane (2007) Droit funéraire et islam en France : I'acceptation des compromis réciproques, Actualité Juridique du Droit Administratif, 36, pp. 1968-1973.

Ragib Yûsuf (1992) Structure de la tombe musulmane d'après le droit musulman, Arabica, 39, pp. 393-403.

Sanson Robert (1947) Les travailleurs nord-africains de la région parisienne, in Robert Gessain Dir., Documents sur l'immigration, cahier $n^{\circ} 2$.

Serfati Émilie (2004) Les rites funéraires des musulmans de Strasbourg à l'aube du XXle siècle, Mémoire de Maîtrise d'histoire des religions, Université M. Bloch, Strasbourg.

Soustiel Jean et Portier Yves (2003) Tombeaux de Paradis, Paris, Monelle Hayot, 250 p.

Sueur Jean-Pierre et Lecerf Jean-René (2005-2006) Bilans et perspectives de la législation funéraire, Rapport d'information, Sénat $n^{\circ} 372$.

Vatin Nicolas et Yerasimos Stéphane (2001) Les cimetières dans la ville, Statut, choix et organisation des lieux d'inhumation dans Istanbul intra-muros, Istanbul/Paris, Institut français d'études anatoliennes Georges Dumézil, 270 p. 


\section{Soraya El Alaoui}

\section{... L'espace funéraire de Bobigny : du cimetière aux carrés musulmans (1934-2006)}

À l'instar de la mosquée de Paris (1926) et de I'hôpital franco musulman (1935), le cimetière musulman de Bobigny symbolise la politique coloniale de la France. Créé par décret dérogatoire (1935), cet espace funéraire ouvrit ses portes en 1937 et fut géré par des fonctionnaires musulmans rattachés à l'hôpital franco-musulman jusqu'en 1996 avant de devenir le carré musulman du cimetière intercommunal. II regroupe des inhumés ayant des nationalités et des profils sociaux très divers et réunit les deux principales branches de l'islam, sunnisme et chiisme. Cet article se propose de décrire et d'analyser sa topographie et les conceptions de l'espace funéraire qu'elle reflète.

\section{The Burial Area in Bobigny: from the Cemetery to the Muslims Sections (1934-2006)}

Like the mosque of Paris (1926) and the French-Muslim hospital (1935), the French-Muslim Bobigny cemetery symbolizes the colonial policy of France. Created by decree derogatory (1935), this burial area opened its doors in 1937. It was managed by Muslims officials attached to the French-Muslim hospital until 1996, before becoming the Muslim section of the local cemetery. It includes buried with diverse nationalities and social profiles and combines the two main branches of Islam, Sunnism and Shiism. This article aims to describe and analyse its topography and the designs that this funerary space reflects.

\section{El espacio funerario de Bobigny: del cementerio a las parcelas musulmanes (1934-2006)}

Tal como la mezquita de Paris (1926) y el hospital franco-musulmán (1935), el cementerio franco-musulmán de Bobigny simboliza la política colonial francesa. Creado por decreto derogatorio (1935), este espacio funerario abrió sus puertas en 1937. Lo administraron funcionares musulmanes, vinculados con el hospital franco-musulmán, hasta 1996, cuando pasó a ser parcelas reservadas del cementerio intercomunal. Agrupa difuntos de nacionalidades y perfiles sociales muy distintos, y reúne las dos ramas principales del islam, sunita y chiita. El artículo pretende describir y analizar la topografía del cementerio así como las concepciones del espacio funerario que él refleja. 